\section{Self-reporting versus parental reporting of physical activity in adolescents: the 11-year follow-up of the 1993 Pelotas (Brazil) birth cohort study}

\author{
Auto-relato de atividade física na adolescência \\ comparado ao relato dos pais: a visita de 11 anos \\ da coorte de nascimentos de Pelotas, Rio Grande \\ do Sul, Brasil, 1993
}

Felipe F. Reichert 1,2 Ana M. B. Menezes 1 Cora Luiza Araújo 1,3 Pedro C. Hallal 1,2

\author{
1 Programa de Pós-graduação \\ em Epidemiologia, \\ Universidade Federal de \\ Pelotas, Pelotas, Brasil. \\ 2 Programa de Pós-graduação \\ em Educação Física, \\ Universidade Federal de \\ Pelotas, Pelotas, Brasil. \\ 3 Faculdade de Nutrição, \\ Universidade Federal de \\ Pelotas, Pelotas, Brasil. \\ Correspondence \\ F. F. Reichert \\ Programa de Pós-graduação \\ em Epidemiologia, \\ Universidade Federal de \\ Pelotas. \\ Rua Marechal Deodoro 1160 \\ Pelotas, RS 96020-220, Brasil. \\ ffreichert@gmail.com
}

\begin{abstract}
The aim of this study was to verify the agreement between different approaches for estimating levels of physical activity in adolescents. One questionnaire was administered to parents and two were administered to the adolescents. This was a crosssectional analysis of data collected in the 20042005 follow-up of the 1993 Pelotas (Brazil) birth cohort study. Parents or guardians answered the following question: "Compared to most children the same age, would you say that your child exercises more, less, or the same amount?"A similar question was addressed to adolescents, as was a detailed questionnaire on physical activity. Agreement between the questionnaires was measured by the weighted kappa statistic. A total of 4,254 adolescents and parents/guardians answered the questionnaires. Kappa values indicated low agreement for all comparisons (kappa $\leq 0.33$ for all analyses). Measurement of physical activity in adolescents is complex, and available instruments should be validated prior to their use.
\end{abstract}

Motor Activity; Adolescent; Cohort Studies

\section{Introduction}

It is crucial to determine the level of physical activity in populations in order to plan interventions and verify the association between physical activity and specific diseases and mortality. However, it is still a challenge for researchers to accurately determine patterns of physical activity in epidemiological studies, particularly in children and adolescents.

Recent years have witnessed an increase in the use of movement sensors, like accelerometers, and these instruments have proven to be a valid alternative 1,2,3. However, the use of these devices in studies with large samples is still limited, mainly because of the equipment's costs. Questionnaires are still the most widely used instruments for determining the level of physical activity in population studies, particularly in low and middle income countries like Brazil 4 .

There is extensive literature on questionnaires that estimate the level of physical activity in children and adolescents. Some questionnaires are answered by the children and adolescents themselves, while in others the questions are addressed to the parents or guardians. The justification in the latter case is that young people lack the capacity to accurately report their levels of physical activity 5 . On the other hand, parents and guardians do not spend 24 hours a day with their children and may thus report erroneously on their levels of physical activity. 
In this context, the current study aimed to verify the agreement between three questionnaires estimating the level of physical activity in adolescents. One of these questionnaires was answered by parents or guardians and the other two by the adolescents.

\section{Methodology}

All the hospital births in 1993 in the city of Pelotas, Rio Grande do Sul State, Brazil, were recorded. The mothers answered a questionnaire, and the newborns were weighed and measured. Subsamples were visited at 1, 3, and 6 months and 1, 4, 6, and 9 years of age. In 2004-2005, all the cohort participants were searched for a new follow-up, the methodological details of which are described elsewhere 6 . The current study was performed with data obtained from the 20042005 follow-up.

Physical activity was estimated in three different ways: level of physical activity as reported by the mother and self-reported by the adolescent, plus a third, more detailed questionnaire addressed to the adolescent. The following question was addressed to the adolescent's mother (or when she was absent or unable to answer, the adolescent's father or guardian): “Compared to most children the same age, would you say that your child exercises: (a) more, (b) less, or (c) the same amount?". A similar question was addressed to the adolescents: "Compared to your friends the same age, do you exercise: (a) more, (b) less, or (c) the same amount?". The questions were asked at different moments in the interview. The mother was unaware of her child's answer, and vice-versa. The in-depth questionnaire answered by the adolescent contained questions on the mode of transportation to school (active versus passive) and leisure-time physical activities in the school setting or out of school (with or without an instructor) in the seven days prior to the interview. Physical education classes were not tabulated, because the level of intensity in the activities is low in both public and private schools in Brazil. Only moderate to vigorous activities were tabulated. The answers to the questionnaire were used to construct a score of minutes of physical activity per week 7 . These instruments had already been used in previous studies 7,8 and were chosen because of the practicality and simplicity of their application in epidemiological studies.

The data were keyed in to Epi Info 6.04 (Centers for Disease Control and Prevention, Atlanta, USA) and transferred to Stata 9.2 (Stata Corp., College Station, USA), where the analyses were performed. The physical activity score con- structed from the questionnaire was divided into tertiles. Thus, each of the three physical activity variables had three categories, indicating "low", "medium", and "high" level of physical activity. The percentage of agreement was calculated between the categories of variables and the kappa index. Kappa is a statistical test for measuring agreement between categorical variables and which discounts the percentage of agreement expected by chance ${ }^{9}$. Kappa values $\leq 0.40$ are interpreted as low agreement, from 0.41 to 0.60 as moderate, and $>0.60$ as high agreement ${ }^{9}$. Since the variables were ordinal, the weighted kappa index was calculated, assigning different weights to disagreements according to the discrepancy's magnitude. We used weights of 1.0 for agreement, 0.5 for one-category disagreement, and 0.0 for two-category disagreement. We performed stratified analyses by gender, body mass index (BMI), and socioeconomic status (as determined by the Brazilian Association of Population Studies) 10 . However, since the results of these stratified analyses were similar to those of the overall sample, only the latter are presented here.

The project was approved by the Research Ethics Committee of the School of Medicine, Federal University in Pelotas. The parents or guardians signed a free and informed consent form, authorizing the children to participate in the interview, and informed consent was obtained from the adolescents.

\section{Results}

During the 2004-2005 follow-up, 4,452 adolescents $(50.8 \%$ females, $72.8 \%$ white) were interviewed (follow-up rate $=87.5 \%$ ). Of these, 172 failed to answer the questions related to physical activity. Likewise, 26 mothers failed to provide valid data on the question referring to their child's level of physical activity. Thus, the maximum number of observations for the analyses was 4,254 . Table 1 provides a description of the sample in relation to demographic and socioeconomic variables, nutritional status, and physical activity. The mean physical activity score was 415 minutes/week (standard deviation - SD = $765)$. More than $99 \%$ of the adolescents were attending school, and $86.5 \%$ of them had two or three physical education classes per week. The majority of the mothers (59.2\%) and adolescents $(66.9 \%)$ reported a similar level of physical activity as compared to other adolescents of the same age.

Table 2 shows a comparison of the mothers' and adolescents' perceptions of the adolescents' level of physical activity. In both this and the sub- 
Table 1

Description of the sample. 1993 Pelotas (Brazil) birth cohort study, 2004-2005 follow-up.

\begin{tabular}{|c|c|c|}
\hline Variable & $\mathrm{n}$ & $\%$ \\
\hline \multicolumn{3}{|l|}{ Gender } \\
\hline Male & 2,192 & 49.2 \\
\hline Female & 2,260 & 50.8 \\
\hline \multicolumn{3}{|l|}{ Age (years) } \\
\hline 10 & 886 & 19.9 \\
\hline 11 & 3,510 & 78.9 \\
\hline 12 & 55 & 1.2 \\
\hline \multicolumn{3}{|l|}{ Family's socioeconomic status * } \\
\hline A & 164 & 3.7 \\
\hline B & 697 & 15.8 \\
\hline C & 1,514 & 34.4 \\
\hline $\mathrm{D}$ & 1,722 & 39.1 \\
\hline$E$ & 309 & 7.0 \\
\hline \multicolumn{3}{|l|}{ Nutritional status ** } \\
\hline Underweight & 313 & 7.1 \\
\hline Normal weight & 3,100 & 69.8 \\
\hline Risk of overweight & 1,029 & 23.2 \\
\hline \multicolumn{3}{|c|}{ Mother's report of adolescent's physical activity } \\
\hline Less exercise than friends & 886 & 20.0 \\
\hline Same amount & 2,619 & 59.2 \\
\hline More exercise than friends & 921 & 20.8 \\
\hline \multicolumn{3}{|c|}{ Adolescent's self-reported physical activity } \\
\hline Less exercise than friends & 776 & 17.5 \\
\hline Same amount & 2,966 & 66.9 \\
\hline More exercise than friends & 693 & 15.6 \\
\hline \multicolumn{3}{|c|}{ Level of physical activity (minutes/week) } \\
\hline$<300$ & 2,496 & 58.2 \\
\hline$\geq 300$ & 1,793 & 41.8 \\
\hline
\end{tabular}

* According to criteria of the Brazilian Association of Population Studies (ABEP) 10;

** According to World Health Organization (WHO) criteria 23 .

Table 2

Mother's report and adolescent's self-reported physical activity. 1993 Pelotas (Brazil) birth cohort study, 2004-2005 follow-up.

\begin{tabular}{|c|c|c|c|}
\hline \multirow[t]{3}{*}{ Mother's report } & \multicolumn{3}{|c|}{ Adolescent's self-report } \\
\hline & More exercise & Same amount & Less exercise \\
\hline & n (\%) & $n(\%)$ & n (\%) \\
\hline More exercise & $364(52.9)$ & $471(16.0)$ & $79(10.2)$ \\
\hline Same amount & $260(37.9)$ & $2,034(68.9)$ & $320(41.3)$ \\
\hline Less exercise & $63(9.2)$ & $444(15.1)$ & $375(48.5)$ \\
\hline Total & $687(100.0)$ & $2,949(100.0)$ & 774 (100.0) \\
\hline
\end{tabular}

Note: kappa $=0.33$; percentage agreement $=79.8 \%$. 
sequent tables, high agreement is shown by the proportions in the diagonals (bold numbers). We placed the percentages in the columns to facilitate visualizing the proportions, but the calculations could also have been performed based on the total from the rows. The kappa for this table was 0.33 (low agreement), and the percentage of agreement was $79.8 \%$.

Table 3 compares the mother's perception to the adolescent's physical activity tertiles, and Table 4 compares the adolescent's perception to the score tertiles. These two tables show similar agreements to each other, but lower than Table 2 .

\section{Discussion}

Determining the population level of physical activity still challenges researchers. The number of available instruments has increased in recent years, but questionnaires are still the most wide- ly used tools, due mainly to their low cost and speed in obtaining data 11 . Still, the accurate determination of levels of physical activity through questionnaires depends on the individual's recall capacity for physical activities. In this sense, applying questionnaires to children and adolescents may pose a limitation, and an alternative has been to address the questions to parents or guardians. It is plausible to assume that the accuracy of answers to questionnaires increases over the course of adult life. However, the minimum age at which an individual is capable of accurately self-reporting his or her level of physical activity remains undetermined.

The comparison of self-reporting by the child or adolescent and reporting by parents or guardians has also been studied to verify fruit and vegetable consumption 12 , anxiety and depression 13, asthma 14, exposure to sunlight and sunscreen use 15 , headache, fatigue, musculoskeletal pain, and medical history 16 , and other health-related behaviors 17. A Chinese study 18

Table 3

Relationship between physical activity score and mother's report of adolescent's physical activity. 1993 Pelotas (Brazil) birth cohort study, 2004-2005 follow-up.

\begin{tabular}{lccc}
\hline Mother's report & & Physical activity score & \\
& Upper tertile & Middle tertile & Lower tertile \\
& $\mathbf{n}(\%)$ & $\mathbf{n}(\%)$ & $206(13.7)$ \\
More exercise & $\mathbf{4 1 2 ( 2 9 . 2 )}$ & $275(20.3)$ & $884(59.0)$ \\
Same amount & $811(57.5)$ & $\mathbf{8 2 4 ( 6 1 . 0 )}$ & $\mathbf{4 1 0 ( 2 7 . 3 )}$ \\
Less exercise & $187(13.3)$ & $253(18.7)$ & $1,500(100.0)$ \\
\hline
\end{tabular}

Note: kappa $=0.13$; percentage agreement $=64.7 \%$.

Table 4

Relationship between physical activity score and adolescent's self-reported physical activity. 1993 Pelotas (Brazil) birth cohort study, 2004-2005 follow-up.

\begin{tabular}{lccc}
\hline Adolescent's self-report & & Physical activity score & Lower tertile \\
& Upper tertile & Middle tertile & $\mathbf{n}(\%)$ \\
\hline More exercise & $\mathbf{n}(\%)$ & $\mathbf{n}(\%)$ & $163(10.8)$ \\
Same amount & $\mathbf{3 1 0 ( 2 1 . 9 )}$ & $198(14.6)$ & $992(65.7)$ \\
Less exercise & $938(66.2)$ & $930(68.7)$ & $354(23.5)$ \\
Total & $168(11.9)$ & $226(16.7)$ & $1,509(100.0)$
\end{tabular}

Note: kappa $=0.11$; percentage agreement $=64.8 \%$. 
and a Japanese study 19 verified the agreement between parent-reported and teacher-reported behavior problems in children. The results of these studies varied substantially, with some comparisons indicating good agreement 14,15, while other studies found low agreement $12,13,16,17,18,19$.

In the present study we verified the agreement between three questionnaires to estimate the level of physical activity in adolescents 11 and 12 years old. The sample was population-based, thus including adolescents of both sexes and different economic and nutritional levels. However, the results were similar for all the categories of these variables. Any generalization of the results to other age brackets should be done with caution, since our study only included adolescents born in 1993. The agreement was higher between the mother's report and the adolescent's self-report than for the physical activity tertiles derived from the detailed questionnaire answered by the adolescent. Even so, the kappa values indicated low agreement for all the comparisons (kappa $\leq$ 0.33 for all the analyses). When adolescents report exercising "the same amount" as classmates, they might be referring to classmates that actually practice some form of physical activity, rather than the total adolescent population. This hypothesis is supported by the observation that the agreement between the physical activity score from the more detailed questionnaire and the other questionnaires was lower than between the two single-question questionnaires. In a similar study, Dowda et al. 20 also found low association between level of physical activity estimated by 531 adolescents and their parents. However, the evaluation of agreement between the answers is limited by the fact that the authors performed analyses by correlation coefficient, when this measure is not necessarily indicative of agreement 21 . The correlation coefficients for both answers (adolescent's self-report and parent's estimate) as compared to an objective and valid measurement of level of physical activity (accelerometer) were also low $(\leq 0.3$ for all the analyses), suggesting that on average, none of the groups accurately reported the levels of physical activity.
Some methodological aspects of the current study should be highlighted. The questionnaires used the terms "physical activity" and "physical exercise". Although there is a conceptual difference between these terms 22 , we strongly believe that the general population does not distinguish between them, and therefore that this issue does not pose a limitation to the study. The three studied instruments are subjective methods. Thus, a limitation to our study is the absence of an objective method that could be considered the gold standard for verifying whether any of the three questionnaires was superior to the others. Still, our findings are extremely relevant, since the weak agreement between the questionnaires indicates that at least two of them have low validity. The answers to the questionnaires had three categories ("less exercise", "the same amount", and "more exercise") and the kappa values and percentages of agreement are dependent on this number of categories. It is thus likely that questionnaires with more options for answers would show lower agreement than found in this study. The study's positive features include the sample's representativeness, the uniqueness of the approach to the theme among Brazilian adolescents, and the application of an appropriate statistical test for assessing agreement between categorical variables. Importantly, the percentage of agreement is a simple measurement, but it does not discount the agreement expected by chance, while the kappa test is indicated to assess the agreement between categorical variables and discounts the agreement expected by chance, and is thus preferable to the percentage of agreement.

Due to the benefits of regular physical activity for adolescents' health 11, and considering that questionnaires are the most widely used instruments for estimating level of physical activity ${ }^{4}$, our findings call attention to the importance of choosing previously validated questionnaires. In light of the lack of strong agreement between the questionnaires, we conclude that at least two of them are not valid. Further studies are needed on this subject, especially employing valid methods for measuring physical activity (like movement sensors, for example). 


\section{Resumo}

O objetivo deste estudo foi verificar a concordância entre diferentes formas de se estimar o nível de atividade física de adolescentes. Um questionário foi aplicado aos pais e outros dois aos adolescentes. O estudo foi transversal aninhado ao acompanhamento de 2004-2005 da coorte de nascimentos de 1993 em Pelotas, Rio Grande do Sul, Brasil. Pais ou responsáveis responderam à questão: "Comparando com a maioria das crianças da mesma idade, o(a) $\mathrm{Sr}$ (a). diria que o seu filho faz mais exercícios que elas, menos exercícios que elas ou a mesma quantidade que elas?". Questão análoga foi aplicada aos adolescentes. Os adolescentes também responderam a um questionário mais detalhado sobre a prática de atividades físicas. A concordância entre os questionários foi avaliada pelo teste kappa ponderado. Um total de 4.254 adolescentes e responsáveis responderam aos questionários. Os valores de kappa indicaram concordância baixa para quaisquer das comparações (kappa $\leq$ 0,33 para todas as análises). A mensuração de atividade física em adolescentes é complexa e os instrumentos disponíveis devem ser validados antes do uso.

Atividade Motora; Adolescente; Estudos de Coortes

\section{Contributors}

F. F. Reichert participated in the data analysis and writing of the manuscript. A. M. B. Menezes and C. L. Araújo contributed to the planning of the cohort follow-up and critical revision of the manuscript. P. C. Hallal collaborated in the critical revision of the manuscript and in the statistical analyses.

\section{Acknowledgments}

The cohort study is supported by the Wellcome Trust. The initial phases of the cohort were funded by the European Union and the Brazilian National Program for Centers of Excellence (PRONEX), National Research Council (CNPq), and Ministry of Health. The CNPq provided a PhD scholarship to F. F. Reichert.

\section{References}

1. Corder K, Brage S, Mattocks C, Ness A, Riddoch C, Wareham NJ, et al. Comparison of two methods to assess PAEE during six activities in children. Med Sci Sports Exerc 2007; 39:2180-8.

2. Brage S, Brage N, Franks PW, Ekelund U, Wareham NJ. Reliability and validity of the combined heart rate and movement sensor Actiheart. Eur J Clin Nutr 2005; 59:561-70.

3. Rowlands AV. Accelerometer assessment of physical activity in children: an update. Pediatr Exerc Sci 2007; 19:252-66.

4. Hallal PC, Dumith SC, Bastos JP, Reichert FF, Siqueira FV, Azevedo MR. Evolução da pesquisa epidemiológica em atividade física no Brasil: revisão sistemática. Rev Saúde Pública 2007; 41:453-60.

5. Sirard JR, Pate RR. Physical activity assessment in children and adolescents. Sports Med 2001; 31:439-54.
6. Araújo CL, Menezes AMB, Vieira MFA, Neutzling MB, Gonçalves H, Anselmi L, et al. The 11-year follow-up of the 1993 Pelotas (Brazil) birth cohort study: methods. Cad Saúde Pública 2010;26:1875-86.

7. Hallal PC, Wells JC, Reichert FF, Anselmi L, Victora CG. Early determinants of physical activity in adolescence: prospective birth cohort study. BMJ 2006; 332:1002-7.

8. Hallal PC, Bertoldi AD, Gonçalves H, Victora CG. Prevalência de sedentarismo e fatores associados em adolescentes de 10-12 anos de idade. Cad Saúde Pública 2006; 22:1277-87.

9. Altman D. Practical statistics for medical research. London: Chapman \& Hall; 1991.

10. Associação Brasileira de Estudos Populacionais. Critério de classificação econômica Brasil. São Paulo: Associação Brasileira de Estudos Populacionais; 2003. 
11. Hallal PC, Victora CG, Azevedo MR, Wells JC. Adolescent physical activity and health: a systematic review. Sports Med 2006; 36:1019-30.

12. Reinaerts E, Nooijer J, Vries NK. Parental versus child reporting of fruit and vegetable consumption. Int J Behav Nutr Phys Act 2007; 4:33.

13. Rockhill CM, Russo JE, McCauley E, Katon WJ, Richardson LP, Lozano P. Agreement between parents and children regarding anxiety and depression diagnoses in children with asthma. J Nerv Ment Dis 2007; 195:897-904.

14. Yawn BP, Wollan P, Kurland M, Bertram S. Comparison of parent and student responses to asthma surveys: students grades 3-12 and their parents from a suburban private school setting. J Sch Health 2006; 76:241-5.

15. Dusza SW, Oliveria SA, Geller AC, Marghoob AA, Halpern AC. Student-parent agreement in self-reported sun behaviors. J Am Acad Dermatol 2005; 52:896-900.

16. Sundblad GM, Saartok T, Engström LM. Childparent agreement on reports of disease, injury and pain. BMC Public Health 2006; 6:276.

17. Karver MS. Determinants of multiple informant agreement on child and adolescent behavior. J Abnorm Child Psychol 2006; 34:251-62.
18. Deng S, Liu X, Roosa MW. Agreement between parent and teacher reports on behavioral problems among Chinese children. J Dev Behav Pediatr 2004; 25:407-14.

19. Satake H, Yoshida K, Yamashita H, Kinukawa N, Takagishi T. Agreement between parents and teachers on behavioral/emotional problems in Japanese school children using the child behavior checklist. Child Psychiatry Hum Dev 2003; 34:111-26.

20. Dowda M, Pate RR, Sallis JF, Freedson PS, Taylor WC, Sirard JR, et al. Agreement between studentreported and proxy-reported physical activity questionnaires. Pediatr Exerc Sci 2007; 19:310-8.

21. Bland JM, Altman DG. Statistical methods for assessing agreement between two methods of clinical measurement. Lancet 1986; 1:307-10.

22. Caspersen CJ, Powell KE, Christenson GM. Physical activity, exercise, and physical fitness: definitions and distinctions for health-related research. Public Health Rep 1985; 100:126-31.

23. World Health Organization. Physical status: the use and interpretation of anthropometry. Report of a WHO Expert Committee. Geneva: World Health Organization; 1995. (WHO Technical Report Series, 854).

Submitted on 11/Feb/2009

Final version resubmitted on 17/Aug/2009

Approved on 23/Sep/2009 